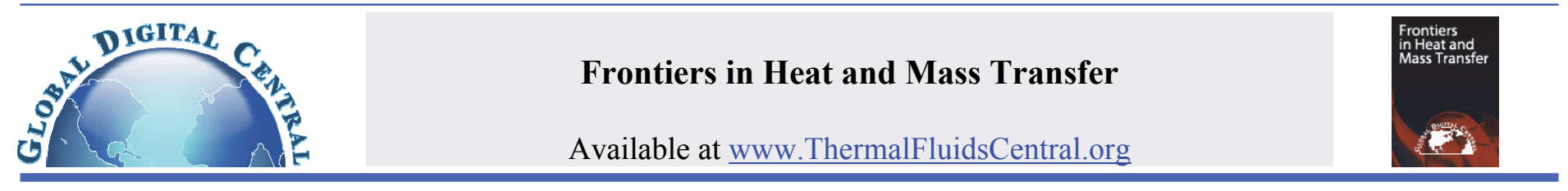

\title{
CONVECTIVE HEAT TRANSFER ANALYSIS IN AN ARCH ENCLOSURE
}

\author{
Manoj Kr. Triveni*, Dipak Sen, RajSekhar Panua \\ National Institute of Technology, Agartala, Tripura, 799055, India
}

\begin{abstract}
A numerical investigation through laminar natural convection has been executed to illuminate the effect of curvature ratio in an arch enclosure filled with water. The left side wall of the cavity is maintained at a higher temperature than that of the right side wall while the other walls are kept insulated. The governing equations such as continuity, momentum and energy equation are solved by finite volume method. The effect of pertinent parameters such as curvature ratio $(1 \leq \mathrm{CR} \leq 1.5)$ and Rayleigh number $\left(1 \times 10^{4} \leq \mathrm{Ra} \leq 1 \times 10^{6}\right)$ and $)$ on heat transfer are calculated by commercial available computational fluid dynamics software, FLUENT 6.3. The fluid flow and heat transfer are shown for fixed Pandtl number 6.5 by streamlines, isotherms and velocity contour. From the investigation, it has been reported that the varying height of the arch cavity and Rayleigh number playing a significant role in heat transfer rate. The variation in heat transfer is calculated in terms of average Nusselt number.
\end{abstract}

Keywords: Arch cavity, Curvature ratio, Natural convection.

\section{INTRODUCTION}

A few decades past, researchers have been working on the forced convection heat transfer for high heat transfer aspect. But increasing the crisis of energy induces the researchers to look towards the natural convection process as wide applications in electronic equipment's, instruments, industries, solar collector, building insulation, nuclear reactor etc. However, among all these applications, heating or cooling from side walls are readily applicable in cooling of electronic goods, chips and transferring of heat in case of solar collector. Abu-Nada et al. (2010) worked for heat transfer enhancement in a differentially heated enclosure using $\mathrm{Al}_{2} \mathrm{O}_{3}$-water and $\mathrm{CuO}$-water nanofluids. It was observed that enclosures having high aspect ratios, experience more deterioration in the average Nusselt number compared to enclosures having low aspect ratios. Asan et al. (2000) have done an experiment on a pitched roof of triangular cross section considering an adiabatic mid-plane wall numerically. From the analysis, it was observed that the heat transfer rate is decreased with increasing the value of aspect ratio and it increases with the increase of Rayleigh number. Braga and Lemos (2005) investigated a square cavity partially filled with a fixed amount of conducting solid material. It has been observed that the overall values of the average Nusselt number are slightly lower than those obtained with the square obstacles. Barletta et al. (2006) have done a numerical study in a 2-D rectangular enclosure. Results revealed that the elliptic boundaries enhance the mean Nusselt number and the dimensionless mean kinetic energy of the fluid as comparison than the rectangular cavity. Basak et al. (2006) have done a numerical analysis of steady laminar natural convection flow in a square cavity. It was examined that the non-uniform heating of the bottom wall produces greater heat transfer rates at the center of the bottom wall than the uniform heating case for all Rayleigh numbers. Basak et al. (2008) used a penalty finite element analysis with bi-quadratic elements which are carried out to investigate the effects of uniform and non-uniform heating conditions in an isosceles triangular enclosure. Results have been concluded that non-uniform heating produces high heat transfer rate at the center of the walls than the uniform heating. However, average Nusselt numbers show overall low heat transfer rate for the non-uniform heating case. Basak et al. (2012) studied the heat transfer analysis by heatlines in a square cavity. Results unfold that the larger enhancement of heat transfer rates were observed for all nanofluids at $\mathrm{Ra}=10^{5}$ and Alumina-Water and Copper-Water exhibit larger enhancement of heat transfer rates. Kandaswamy et al. (2007) have done an analysis in a square cavity using a heating plate inside it. The effect of position and aspect ratio of heated plate on heat transfer and flow were addressed. Results signify that the increase of $\mathrm{Gr}$ increased the heat transfer rate in both vertical and horizontal positions of the plate. Khanafer et al. (2003) have investigated heat transfer enhancement in a two-dimensional enclosure utilizing nanofluids for various pertinent parameters. It was found that the suspended nanoparticles substantially increase the heat transfer rate at any given Grashof number. Nardini and Paroncini (2012) have done a work on square cavity with discrete sources. The temperature distribution in the air and the heat transfer coefficient are measured experimentally by holographic interferometry and compared the numerical results obtained with fluent. The size and position of the heat sources which influence the velocity and fluid flow is observed in this investigation. Nityadevi et al. (2007) performed an investigation in a rectangular cavity with partially active side walls. The result was found that the heat transfer increases with an increase in the aspect ratio. Oztop and Bilgen (2006) worked on a square cavity with internal heat generation. Results have been obtained for various geometrical parameters specifying the height, thickness and position of the partition and for Rayleigh numbers $\left(10^{3}-10^{6}\right)$. It was concluded that the heat transfer is increasing for both internal and external Rayleigh number. Also, it decreases gradually with the increase in partition height and thickness. Paroncini et al. (2012) performed a numerical and experimental analysis in a square enclosure with partially active side walls. It was found that the heat transfer increases with the increase of number of strips. Pesso and Piva (2009) worked on laminar natural convection in a

*Corresponding author.Email: triveni_mikky@yahoo.com 
square cavity. The investigation has done by both numerically and theoretically. Based on physical argument, heat transfer correlation is proposed and valid for all Prandtl and Gay-Lussac number. Roy and Basak (2005) have performed numerically using a Galerkin finite element method with bi-quadratic rectangular elements. It was noticed that in case of uniform heating, the heat transfer rate is very high at the right edge of the bottom wall and almost uniformly on the rest part of the bottom wall. In contrast, for the case of non-uniform heating the heat transfer rate reaches its maximum value at the center of both the heated walls. Sathiyamoorty et al. (2007) investigated heat transfer in a square cavity filled with porous medium. The results were found for the range of parameters Rayleigh number $\mathrm{Ra}, 10^{3} \leq \mathrm{Ra} \leq 10^{6}$, Darcy number Da, $10^{-5} \leq \mathrm{Da} \leq 10^{-3}$, and Prandtl number $\operatorname{Pr}, 0.2 \leq \operatorname{Pr} \leq 100$. the average Nusselt number in general increases with the increase of Da and Ra. Seikhzadeh et al. (2011) worked in square cavity with partially active side walls filled with $\mathrm{Cu}$-water nanofluid. It was observed that the average Nusselt number increases with increasing both the Rayleigh number and the volume fraction of the nanoparticles. Moreover, the maximum average Nusselt number for the high and the low Rayleigh numbers occur for the bottom-middle and the middle-middle locations of the thermally active parts. Varol et al. (2011) have worked on natural convection heat transfer in an inclined fin attached square enclosure both experimentally and numerically. It was observed that the heat transfer can be controlled by attaching an inclined fin onto the wall.

The above brief survey illustrates that the many researchers are worked on triangular, rectangular, square, rhombus, quadrantal cavities. But no work has yet been done for heat transfer analysis in arch cavity. Hence, the main aim of this work is to present the effect of the shape of the cavity in fluid flow and temperature field and to calculate the heat transfer rate. It might be possible that the current work may be helpful to the other researchers or designer to short out the cooling problem from the complex shape of the electronic equipment's as well heat transfer from solar collectors.

\section{PROBLEM DESCRIPTION AND MATHEMATICAL FORMULATION}

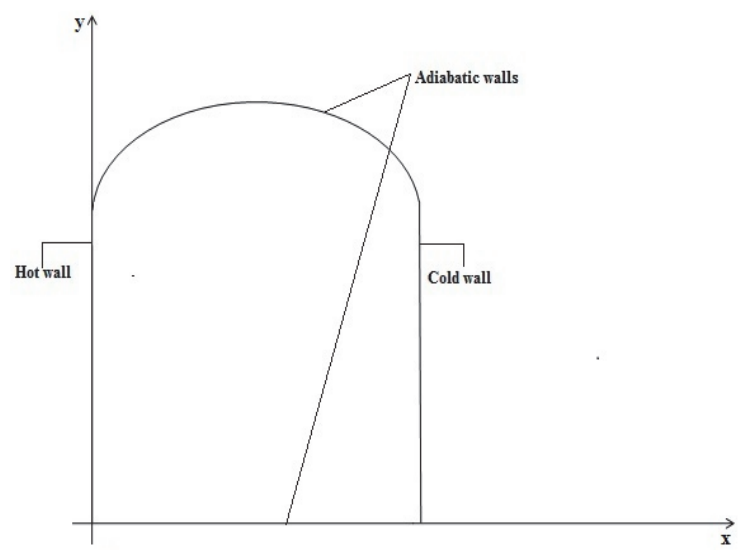

Fig. 1 Physical model of Arch cavity

A schematic diagram of the physical domain has been shown in Fig.1. The vertical walls are maintained at different isothermal temperature whereas other walls are kept insulated. Plexiglas is used as an insulating material for insulated walls and aluminum for thermally active walls. The curvature ratio of the cavity is varying from 1-1.5.

\subsection{Governing equations}

The problem has been solved on certain assumption that

I. There is no radiation heat transfer will takes place inside the enclosure.

II. The fluid filled in the enclosure is viscous, incompressible Newtonian fluid. Boussinesq approximation is used for fluid flow.
III. Gravitational force act over the entire volume in downward direction.

IV. All the fluid properties would be constant except density variation in the $y$-momentum equation.

The governing equation of 2-D, incompressible, steady state and laminar natural convection flow using conservation equation can be written in dimensional form:

as:

$\frac{\partial u}{\partial x}+\frac{\partial v}{\partial y}=0$

$u \frac{\partial u}{\partial x}+v \frac{\partial u}{\partial y}=-\frac{1}{\rho} \frac{\partial p}{\partial x}+v\left(\frac{\partial^{2} u}{\partial x^{2}}+\frac{\partial^{2} u}{\partial y^{2}}\right)$

$u \frac{\partial v}{\partial x}+v \frac{\partial v}{\partial y}=-\frac{1}{\rho} \frac{\partial p}{\partial y}+v\left(\frac{\partial^{2} v}{\partial x^{2}}+\frac{\partial^{2} v}{\partial y^{2}}\right)+g \beta\left(T-T_{0}\right)$

$u \frac{\partial T}{\partial x}+v \frac{\partial T}{\partial y}=\alpha\left(\frac{\partial^{2} T}{\partial x^{2}}+\frac{\partial^{2} T}{\partial y^{2}}\right)$

By using dimensionless parameters such as

$$
\begin{aligned}
& X=\frac{x}{H}, Y=\frac{y}{H}, U=\frac{u H}{\alpha}, V=\frac{v H}{\alpha}, \theta=\frac{T-T_{c}}{T_{h}-T_{c}}, \\
& P=\frac{p H^{2}}{\rho \alpha^{2}}, \operatorname{Pr}=\frac{v}{\alpha}, R a=\frac{g \beta\left(T_{h}-T_{c}\right) H^{3}}{\alpha v}
\end{aligned}
$$

The dimensionless governing equation can be written as $\frac{\partial U}{\partial X}+\frac{\partial V}{\partial Y}=0$

$U \frac{\partial U}{\partial X}+V \frac{\partial U}{\partial Y}=-\frac{\partial P}{\partial X}+\operatorname{Pr}\left(\frac{\partial^{2} U}{\partial X^{2}}+\frac{\partial^{2} U}{\partial Y^{2}}\right)$

$U \frac{\partial V}{\partial X}+V \frac{\partial V}{\partial Y}=-\frac{\partial P}{\partial Y}+\operatorname{Pr}\left(\frac{\partial^{2} V}{\partial X^{2}}+\frac{\partial^{2} V}{\partial Y^{2}}\right)+R a \operatorname{Pr} \theta$

$U \frac{\partial \theta}{\partial X}+V \frac{\partial \theta}{\partial Y}=\left(\frac{\partial^{2} \theta}{\partial X^{2}}+\frac{\partial^{2} \theta}{\partial Y^{2}}\right)$

And dimensionless boundary conditions are:

$$
\begin{aligned}
& \mathrm{U}(\mathrm{X}, 0)=\mathrm{U}(\mathrm{X}, 1)=\mathrm{U}(0, \mathrm{Y})=\mathrm{U}(1, \mathrm{Y})=0 \\
& \mathrm{~V}(\mathrm{X}, 0)=\mathrm{V}(\mathrm{X}, 1)=\mathrm{V}(0, \mathrm{Y})=\mathrm{V}(1, \mathrm{Y})=0 \\
& \theta(0, \mathrm{Y})=1, \theta(1, \mathrm{Y})=0 \\
& \frac{\partial \theta}{\partial Y}(X, 0)=\frac{\partial \theta}{\partial Y}(X, 1)=0 \text { between } 0<X<1
\end{aligned}
$$

\section{NUMERICAL APPROACH}

The problem has solved by commercial available software; FLUENT 6.3 which hire finite volume method. For fluid based problem, FVM is providing better flexibility and preciseness. SIMPLE algorithm coupled with pressure and velocity is used to solve the dimensionless governing equations (6-9) with the corresponding boundary conditions (10). Momentum and energy equations are discretized by second order upwind technique while the pressure interpolation is done by PRESTO 
scheme. The heat transfer coefficient in term of local Nusselt number can be expressed as:

$$
N u_{x}=\frac{h L}{k}=-\frac{\partial \theta}{\partial n}
$$

Where $\mathrm{h}$ is heat transfer coefficient, $\theta$ is a dimensionless temperature and $n$ denotes the normal direction to the plane.

The average nusselt number can be written as:

$$
N u=\frac{1}{L} \int_{0}^{L} N u_{x} d y
$$

\section{GRID INDEPENDENCY TEST AND VALIDATION}

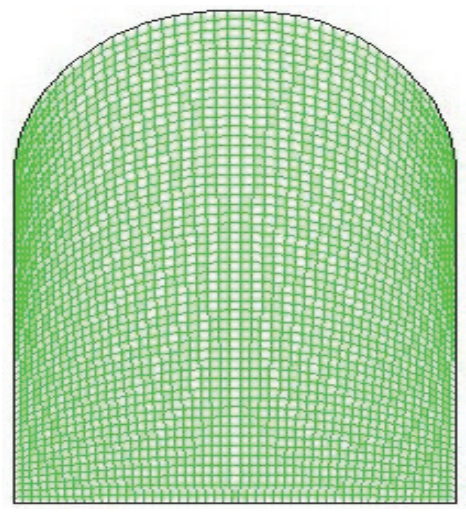

Fig. 2 Grid structure for arch cavity

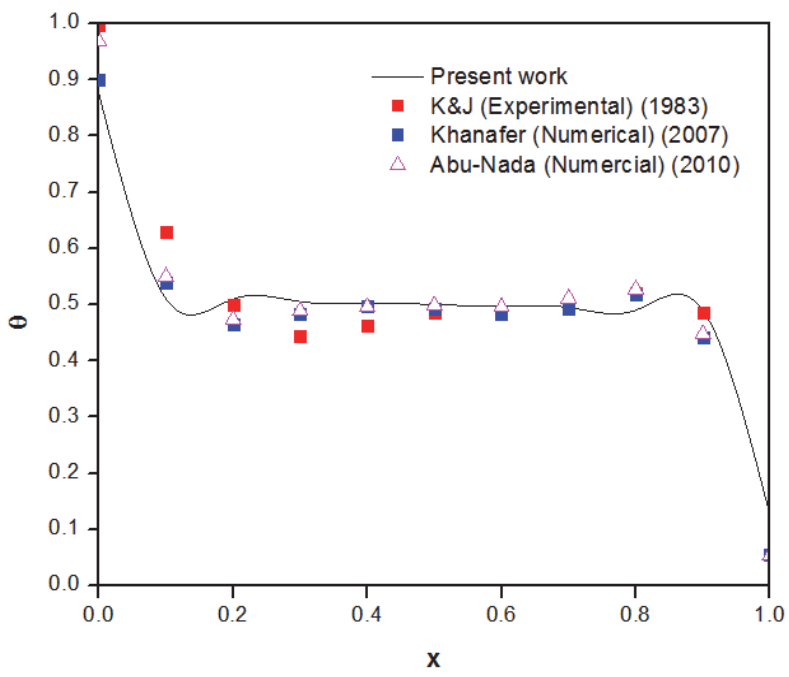

Fig. 3 Comparison between present work and other published data for temperature distribution along the width of the enclosure for nanofluid at $\mathrm{Ra}=1 \times 10^{5}$ and $\operatorname{Pr}=0.7$

In this study, five different grid sizes $(41 \times 41,51 \times 51,61 \times 61,71 \times 71$ and $81 \times 81$ ) are adopted to check the mesh independence. A uniform grid structure in arch cavity is shown in fig 2. A detailed grid independency test has been performed for average Nusselt number at $\mathrm{Ra}=1 \times 10^{5}$. The table 1 elucidate that the relative error value of the average Nusselt number is very less for grid size $51 \times 51$ and $61 \times 61$ compare to others. Since, at high grid size solution will take more time to converge the solution and the accuracy level is almost same. So $51 \times 51$ grid adopted for computational time limits.

Table 1: Relative error data at different grid size

\begin{tabular}{|c|c|c|cc|c|c|}
\hline Grid size & $\mathbf{4 1} \times \mathbf{4 1}$ & $\mathbf{5 1} \times \mathbf{5 1}$ & $\mathbf{6 1} \times \mathbf{6 1}$ & $\mathbf{7 1} \times \mathbf{7 1}$ & $\mathbf{8 1} \times \mathbf{8 1}$ \\
\hline $\mathbf{N u}$ & 4.88 & 4.894 & 4.897 & 4.881 & 4.893 \\
\hline $\begin{array}{c}\text { Relative } \\
\text { Error (\%) }\end{array}$ & \multicolumn{2}{|c}{0.31} & 0.061 & 0.33 & 0.25 \\
\hline
\end{tabular}

The present work is validated with experimental result of Krane and Jesse (1983) and numerical results of Khanefer (2007) and AbuNada (2010) at $\mathrm{Ra}=1 \times 10^{5}$ and $\mathrm{Pr}=0.7$. The above dimensionless temperature and position graph shows the values of experimental and numerical results are fluctuating within $\pm 12 \%$.

\section{RESULT AND DISCUSSIONS}

A numerical simulation analysis has been conducted to examine the effects on flow regimes due to change of curvature ratio (1 to 1.5) and Rayleigh number $\left(10^{4}-10^{6}\right)$.

Figure 4 demonstrates the fluid flow at different curvature ratio and $\mathrm{Ra}$. The row of the figure 4 and 5 are showing the effect of shape of the cavity while column of the figure effect of Rayleigh number. Fig. 4 (a) present the case of $\mathrm{Ra}=10^{4}$ and $\mathrm{CR}=1$ where the streamline is in parabolic shape at the center but as the CR increases it started to turn into the circular and at $\mathrm{CR}=1.5$, the streamline turn into fully circular shape. The change in curvature ratio includes additional number of water molecules for heat transport. This increment in numbers of molecule increases the heat transfer rate. At Rayleigh number $10^{5}$, the cell length increases and distinguished into the oval shape which is shown in fig 4b. Further, as the Rayleigh number increases to higher value, the cell length extended and turned into the peculiar shape inside the cavity which display in figure 4 (c-d). It is also noticeable that the streamlines are spreading throughout the cavity and concentrating towards the thermally active walls. The deformation and concentration of the streamlines cell signifies that the boundary layer diminishes by increasing the flow strength of the fluid with the increase in Rayleigh number.

Figure 5 illustrates the temperature distribution inside the cavity for various curvature ratio and Rayleigh number. The thickness of the thermal boundary layer is directly related to the viscous effect of the fluid. Higher the thickness of the thermal boundary layer induces high viscous effect and less the heat transfer. The thermal plumes are started from the left corner of the cavity, move upward, flow throughout the cavity and impinged to the right corner of the cavity. As the curvature ratio increases, shown in Figure 5a, the plumes are shifted towards the cold wall and at higher value of CR, it sticks to the cold wall. Also the motions of the isotherms are very slow at low Rayleigh number which indicates the weak flow strength of the fluid. Also the viscous effect is dominating over convection at low Ra. However, as the Rayleigh number increases the flow strength of the fluid increases and the temperature gradient between hot and cold wall become more severe. At high Rayleigh number, shown in figure $5 \mathrm{~d}$, the isotherms become parallel to each other at the center of the cavity. The viscous effect of the fluid decreases with the increment in Ra which leads to increase the flow strength of the fluid. The convective heat transfer started to dominate over viscosity of the fluid at high Rayleigh number because of increment in the flow strength of the fluid which leads to enhance the heat transfer rate. The velocity vector has been shown in figure $5 \mathrm{e}$ which signifies the flow direction and temperature distribution of the fluid between the hot and cold wall. 

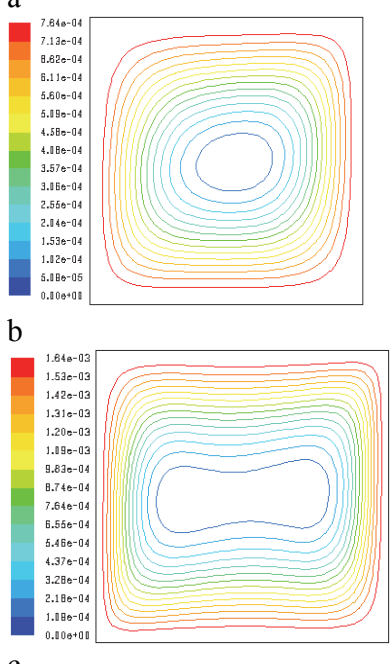

c

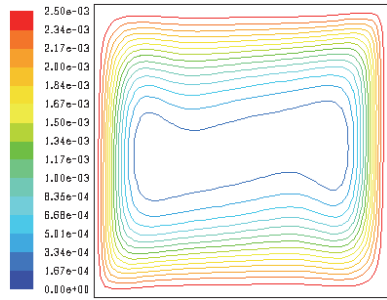

d

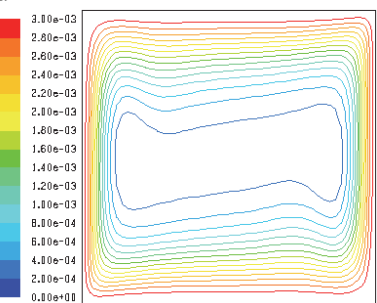

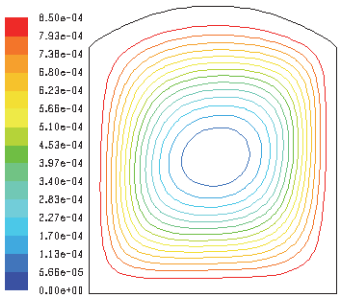
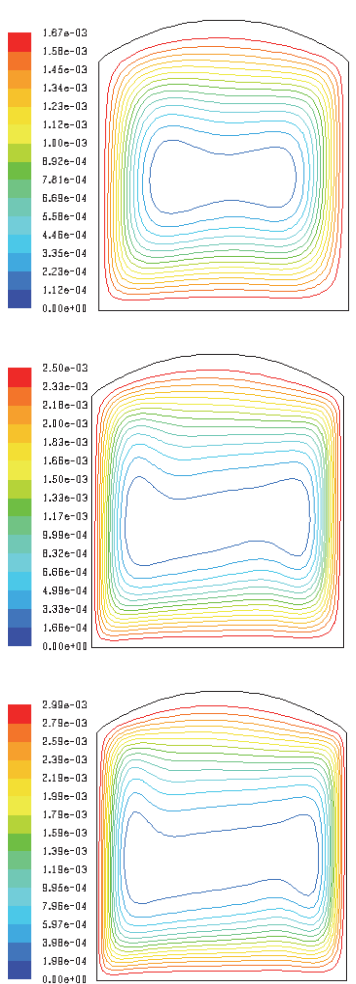
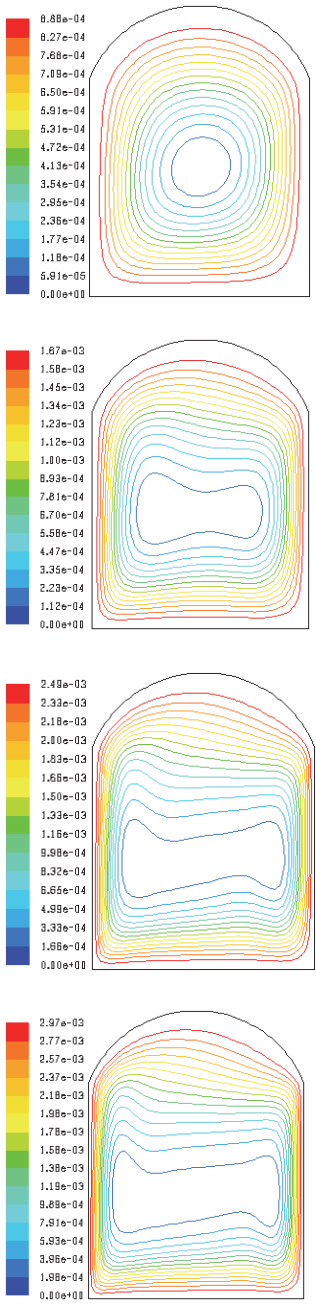
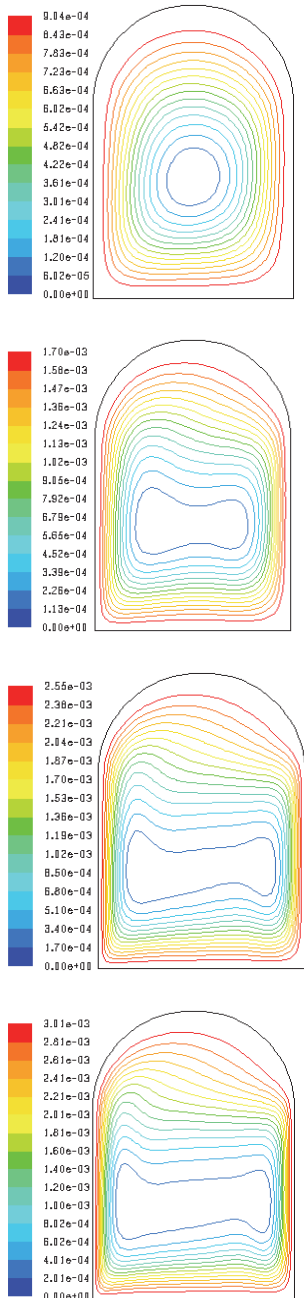

Fig. 4 Variation in Streamlines with curvature ratio 1- 1.5 (from left to right) at (a) $\mathrm{Ra}=1 \times 10^{4}$ (b) $\mathrm{Ra}=1 \times 10^{5}$ (c) $\mathrm{Ra}=5 \times 10^{5}$ and (d) $\mathrm{Ra}=1 \times 10^{6}$.

Table 2: Values of Nusselt number at different Ra and CR

\begin{tabular}{|c|c|c|c|c|}
\hline & $\mathbf{C R}=\mathbf{1}$ & $\mathbf{C R}=\mathbf{1 . 1 7}$ & $\mathbf{C R}=\mathbf{1 . 3 3}$ & $\mathbf{C R}=\mathbf{1 . 5}$ \\
\hline $\mathbf{R A}=\mathbf{1 \times \mathbf { 1 0 } ^ { \mathbf { 4 } }}$ & 1.81 & 2.17 & 2.35 & 2.31 \\
\hline $\mathbf{R A}=\mathbf{1} \times \mathbf{1 0}^{\mathbf{5}}$ & 4.59 & 4.88 & 4.98 & 5.1 \\
\hline $\mathbf{R A}=\mathbf{5} \times \mathbf{1 0}^{\mathbf{5}}$ & 7.6 & 7.86 & 7.88 & 8.03 \\
\hline $\mathbf{R A}=\mathbf{1} \times \mathbf{1 0}^{\mathbf{6}}$ & 9.36 & 9.61 & 9.6 & 9.67 \\
\hline
\end{tabular}

Table 2 illustrates that the variation of average Nusselt number with Rayleigh number. The thickness of the thermal boundary layer demonstrates the viscous effect of the fluid. More the thickness of the thermal boundary layer lesser will be the heat transfer. At low Rayleigh number the sluggish velocity and convection induced the increase of the thickness of boundary layer. Also, conduction heat transfer dominates over the convection heat transfer. As the Rayleigh number increases, the velocity of the fluid dominates over the viscous effect of fluid due to which convective heat transfer will be the prime source of heat transfer. The increment of buoyancy effect and reduction of the viscosity of the fluid attenuate the thickness of thermal boundary layer due to which the heat transfer increases. Hence, the numerical data shown in table 2 appears that the Nusselt number increases with the increase of $\mathrm{Ra}$ and $\mathrm{CR}$.

\section{CONCLUSIONS}

A numerical study has been performed in an arch cavity. The results are validated with the published experimental and numerical results. The analysis is done for $\mathrm{Ra}=10^{4}-10^{6}$. The objective of the current investigation is to study the effect of Rayleigh number and curvature ratio on the fluid flow and heat transfer characteristics. Fluid flow and temperature distributions have shown by streamlines and isotherms as well as heat transfer is calculated in term of average Nusselt number. From the investigation it has been observed that the convective heat transfer is dominating over conduction at high Rayleigh number. The heat transfer rate is increasing with the increase in curvature ratio. As expected, increase in Rayleigh number leads to increase the average Nusselt number. 


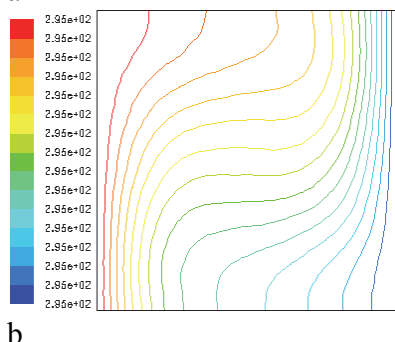

b

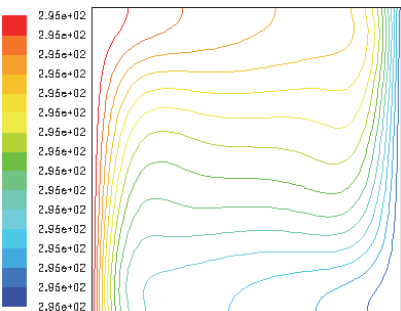

c

Isotherms
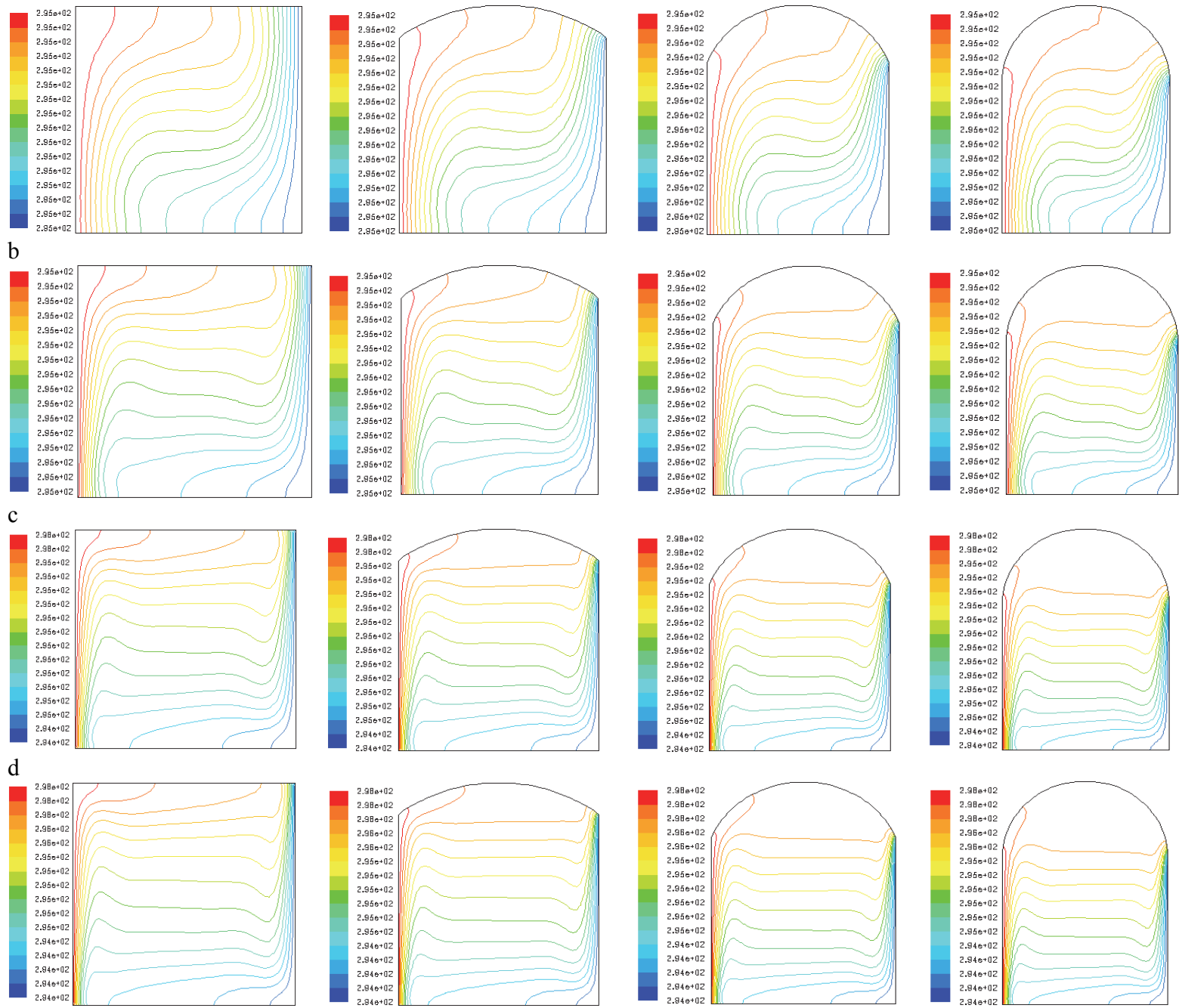

$2.956+02$
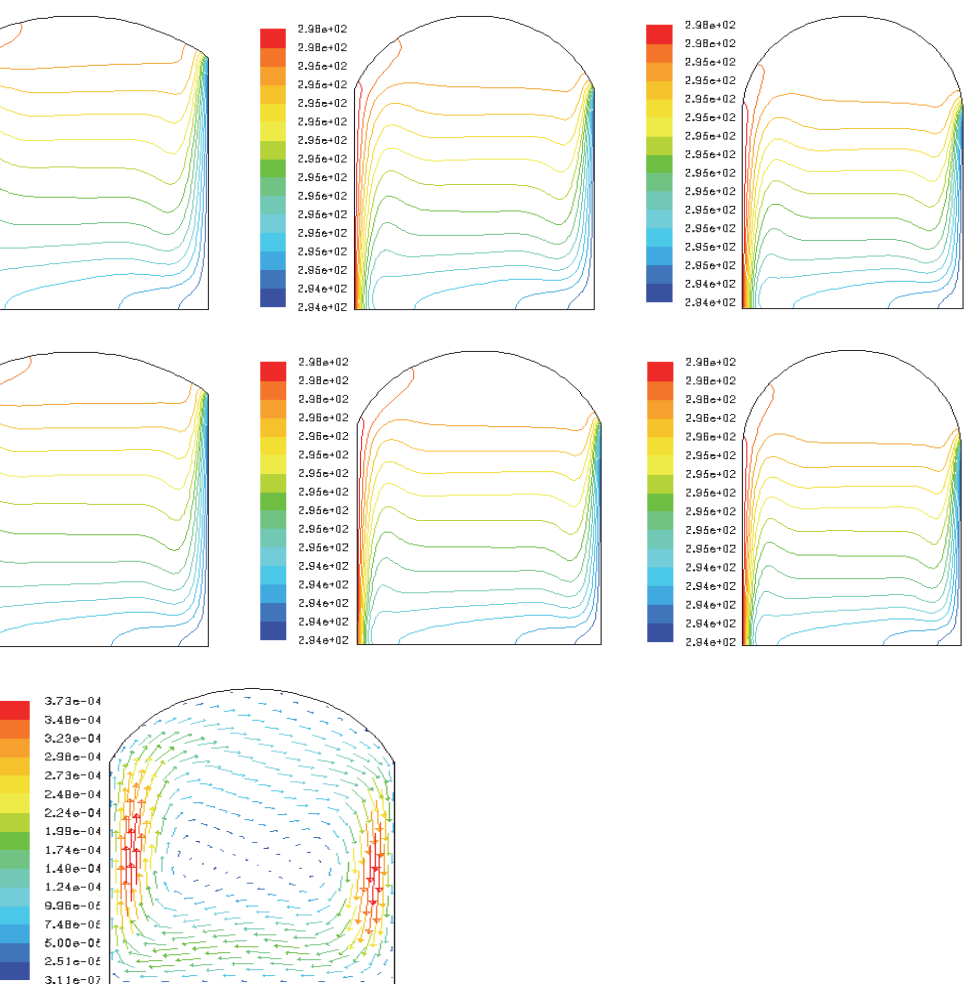

Fig. 5 Variation in isotherms with curvature ratio $1-1.5$ (from left to right) at (a) $\mathrm{Ra}=1 \times 10^{4}$

(b) $\mathrm{Ra}=1 \times 10^{5}$ (c) $\mathrm{Ra}=5 \times 10^{5}$ and (d) $\mathrm{Ra}=1 \times 10^{6}$.

\section{NOMENCLATURE}

g acceleration due to gravity $\left(\mathrm{m} / \mathrm{s}^{2}\right)$

$\mathrm{k}$ thermal conductivity of the fluid $(\mathrm{W} / \mathrm{m} \cdot \mathrm{K})$

$\mathrm{H} \quad$ height of the enclosure (m)

$\mathrm{L} \quad$ width of the enclosure $(\mathrm{m})$

$\mathrm{p} \quad$ pressure $(\mathrm{Pa})$

$\mathrm{P} \quad$ non-dimensional pressure

$\mathrm{u}, \mathrm{v} \quad$ velocity in $\mathrm{x}$ and $\mathrm{y}$ direction $(\mathrm{m} / \mathrm{s})$

$\mathrm{U}, \mathrm{V} \quad$ non-dimensional velocity in $\mathrm{x}$ and $\mathrm{y}$ direction

$\mathrm{T} \quad$ temperature $(\mathrm{K})$

$\operatorname{Pr} \quad$ prandtl number, $(\mathrm{v} / \alpha)$

$\mathrm{Ra} \quad$ Rayleigh number

$\mathrm{Nu}_{\mathrm{x}} \quad$ local Nusselt number
$\mathrm{Nu} \quad$ average Nusselt number

CR curvature ratio

Greek Symbols

$\begin{array}{ll}\alpha & \text { thermal diffusivity }\left(\mathrm{m}^{2} / \mathrm{s}\right) \\ \beta & \text { thermal expansion coefficient }(1 / \mathrm{K}) \\ \theta & \text { dimensionless temperature } \\ \Psi & \text { stream function } \\ \Psi & \text { non-dimensional stream function } \\ \mu & \text { dynamic viscosity }(\mathrm{kg} / \mathrm{m}-\mathrm{s}) \\ v & \text { kinematic viscosity }\left(\mathrm{m}^{2} / \mathrm{s}\right) \\ \rho & \text { density of the fluid }\left(\mathrm{kg} / \mathrm{m}^{3}\right) \\ \text { Subscripts } & \\ \text { h } & \text { hot wall } \\ \text { c } & \text { cold wal }\end{array}$




\section{ACKNOWLADGEMENT}

The authors wish to express their very sincerely thanks to the reviewers for their valuable comments and suggestions.

\section{REFERENCES}

Abu-Nada, E., Masoud, Z., Oztop, H.F. and Campo, A., 2010, "Effect of Nanofluid Variable Properties on Natural Convection in Enclosure," Int. J. of Thermal Science, 49, 479-491.

http://dx.doi.org/10.1016/j.ijthermalsci.2009.09.002

Asan, H. and Namil, L., 2000, "Laminar Natural Convection in a Pitched Roof of Triangular Cross Section: Summer Day Boundary Condition," Energy and Buildings, 33(1), 69-73.

http://dx.doi.org/10.1016/S0378-7788(00)00066-9

Barga, E.J. and Lemos, 2005, "Laminar Natural Convection in Cavities Filled with Circular and Square Rods," Int. Communication in Heat and Mass Transfer, 32, 1289-1297.

http://dx.doi.org/10.1016/j.icheatmasstransfer.2005.07.014

Barletta, A., Nobile, E., Pinto, F., Schio, E.R. and Zanchini, E., 2006, "Natural Convection in A 2D- Cavity with Vertical Isothermal Walls: Cross Validation of Two Numerical Solutions," Int. J. of Thermal Science, 45, 917-922.

http://dx.doi.org/10.1016/i.ijthermalsci.2005.12.002

Basak, T., Roy, S. and Balakrishnan, A. R., 2006, "Effects of Thermal Boundary Conditions on Natural Convection Flows within a Square Cavity," Int. J. Heat and Mass Transfer, 49, 4525-4535.

http://dx.doi.org/10.1016/j.ijheatmasstransfer.2006.05.015

Basak, T., Roy, S., Babu, S.K. and Balakrishnan, A.R., 2008, "Finite Element Analysis of Natural Convection Flow in a Isosceles Triangular Enclosure due to Uniform and Non- Uniform Heating At The Side Walls," Int. J. Heat and Mass Transfer, 51, 4496-4505. http://dx.doi.org/10.1016/j.ijheatmasstransfer.2007.12.018

Basak. T and Chamkha Ali J., 2012, "Heatline Analysis on Natural Convection For Nanofluids Confined Within Square Cavities With Various Thermal Boundary Conditions," Int. J. Heat and Mass Transfer, 55, 5526-5543.

http://dx.doi.org/10.1016/j.ijheatmasstransfer.2012.05.025

Kandaswamy, P., Lee, J. and Hakeen, A.K. Abdul, 2007, "Natural Convection in a Square Cavity in The Presence Of Heated Plate," Nonlinear Analysis: Modelling and Control, 12(2), 203-212. http://www.lana.lt/journal/25/Kandaswamy.pdf

Khanafer, K., Vafai, K. and Lightstone, M., 2003, "Buoyancy-Driven Heat Transfer Enhancement in a Two Dimensional Enclosure Utilizing Nanofluids". Int. J. Heat Mass Transfer, 46, 3639-3653.

\section{http://dx.doi.org/10.1016/S0017-9310(03)00156-X}

Krane, R. J. and Jessee, J., 1983, "Some Detailed Field Measurements for a Natural Convection Flow In A Vertical Square Enclosure," in: 1st ASME-JSME Thermal Engineering Joint Conference, Vol. 1, 323-329.

Nardini, G. and Paroncini F., 2012, "Heat Transfer Experiment on Natural Convection in A Square Cavity with Discrete Sources," Heat Mass Transfer, 48, 1855-1865. http://dx.doi.org/10.1007/s00231-012-1026-6

Nithyadevi, N., Kandaswamy, P. and Lee, J., 2007, "Natural Convection in a Rectangular Cavity with Partially Active Side Walls," Int. J. Heat and Mass Transfer, 50, 4688-4697.

http://dx.doi.org/10.1016/j.ijheatmasstransfer.2007.03.050

Paroncini, M., Carvo, F., Montucchiari, A. and Nardini, G., 2012, “A Numerical and Experimental Analysis on Natural Convection Heat Transfer in a square Enclosure with Partially Active Side Walls," Experimental Thermal and Fluid Science, 36, 118-125. http://dx.doi.org/10.1016/i.expthermflusci.2011.09.004

Pesso, T. and Piva, S., 2009, "Laminar Natural Convection in a Square Cavity: Low Prandtl Numbers and Large Density Differences," Int. J. Heat and Mass Transfer, 52, 1036-1043.

http://dx.doi.org/10.1016/j.ijheatmasstransfer.2008.07.005

Roy, S. and Basak, T., 2005, "Finite Element Analysis of Natural Convection Flows in a Square Cavity with Non-Uniformly Heated Wall(S)," Int. J. of Engineering Science, 43, 668-680.

http://dx.doi.org/10.1016/i.ijengsci.2005.01.002

Sathiyamoorty, M., Basak, T., Roy, S. and Pop, I., 2007, "Steady Natural Convection Flow in a Square Cavity Filled with Porous Medium for Linearly Heated Side Wall(s)," Int. J. Heat and Mass Transfer, 50, 1892.1901.

http://dx.doi.org/10.1016/j.ijheatmasstransfer.2006.10.010

Sheikhzadeh, G. A., Arefmanesh, A., Kheirkhah, M. H. and Abdollahi, R. 2011, "Natural Convection of Cu-Water Nanofluid in a Cavity with Partially Active Side Walls," European Journal of Mechanics B/Fluids, 30, 166-176.

http://dx.doi.org/10.1016/j.euromechflu.2010.10.003

Varol, Y., Oztop, H.F., Ozgen, F. and Koca, A., 2011, "Experimental and Numerical Study on Laminar Natural Convection in a Cavity Heated from Bottom Due To an Inclined Fin," Heat and Mass Transfer, 48, 61-70. http://dx.doi.org/10.1007/s00231-011-0843-3 